\title{
30 Tokyo 2020 from the regional sidelines
}

\author{
Isaac Gagné
}

The Tokyo 2020 Olympics and Paralympics are being touted by government officials and the mass media as an event that will bring the nation together, and as a source of anticipation and inspiration for motivating people across the country. It has also been called the "Recovery Olympics" (fukko gorin), referring to its perceived role in both contributing to and showcasing the recovery of the Tohoku region of northeastern Japan after the March 11, 2011 earthquake, tsunami, and nuclear disaster, known collectively as "3.11."

The 2020 Olympics are certainly a national project - the financial and infrastructural scale of hosting the event has required the mobilization of resources from all sectors and all regions of the country. However, the physical fact that the Olympics will be held in the Greater Tokyo Area means that, with the exception of the relocated marathon (Sapporo), cycling events (Shizuoka Prefecture), and preliminary soccer matches (Hokkaido and Miyagi Prefecture), softball and baseball matches (Fukushima Prefecture), the tangible experience of the Olympics event itself is not national, but localized around Tokyo.

To be sure, the excitement for the Olympics is not limited to Tokyo, and in whatever country the Olympics are held, it always has a national dimension which extends beyond the geographic boundaries of the host city itself. Moreover, Tokyo is massive - the Greater Tokyo Area comprising Tokyo, Chiba, Saitama, and Kanagawa accounts for over 38 million residents, nearly $30 \%$ of Japan's population - and thus in demographic terms alone, holding the Olympics in Tokyo makes it a mass national event. And yet, the 2020 Olympics has not been openly welcomed by all corners of the country, especially rural communities still suffering from the 3.11 disaster. So what does the Tokyo 2020 Olympics mean to the other roughly $70 \%$ of the Japanese population not living in or near Tokyo? 


\section{The view from the regional bleachers}

Skepticism regarding the national and metropolitan governments' motives for hosting the Olympics in Tokyo, as well as regarding the purported benefits of the Olympics to areas outside of the metropolitan region, has shadowed the excitement of the official announcement from the beginning. In a 2016 national survey, $31 \%$ of respondents from outside of Tokyo worried that the 2020 Olympics would worsen the gap between Tokyo and other regions. ${ }^{1}$ In addition, alongside criticisms of the economic effects, there have been vocal critics from the periphery regions, most notably in Tohoku, the northeastern part of Japan that was devastated by 3.11. As of January 2020 , over 48,000 people remained displaced due to the nuclear disaster as well as the tsunami that destroyed coastal communities. In the same survey from 2016, 53\% of respondents from outside of Tokyo (versus $45 \%$ of Tokyo residents) felt that post-3.11 reconstruction has been slowed due to Olympic preparations. And in contrast to the national government's attempts to promote the Olympics as the "Recovery Olympics," $52 \%$ of all respondents did not feel that the Olympics held value as showcasing Japan's recovery.

\section{The "Recovery Olympics": whose recovery?}

The Tokyo 2020 Olympics has been touted as the "Recovery Olympics" since 2012. After the failed 2009 bid for Tokyo 2016, Tokyo's new bid for 2020 began in April 2011, less than a month after the 3.11 disaster. At the time, the governor of Tokyo, Ishihara Shintaro, proclaimed that the Olympics would "cheer up the nation," and the candidate profile submitted to the International Olympic Committee in 2012 characterized Tokyo 2020 as the "Recovery Olympics."

However, for many in the regions affected by 3.11 , the wounds are still raw, and healing has been slow. In March 2014, about six months after Tokyo secured the 2020 Olympics, I conducted field research in Natori, Miyagi Prefecture with displaced survivors of the tsunami who were living in temporary housing. Many survivors voiced concern that all of the excitement for the Tokyo Olympics had distracted national attention away from the fact that there were still hundreds of thousands of displaced survivors waiting for their hometowns to be rebuilt. Many also worried that material and human resources needed for reconstruction would be redirected to Tokyo to build Olympic venues. On a research trip to the small town of Zao in Miyagi Prefecture, which was spared from the tsunami but which had many residents who lost family members or had themselves fled from damaged coastal areas, residents voiced similar concerns about the 
financial strain on the national budget. The plan to have the Olympic torch relay start in Fukushima and pass through the damaged regions also did not draw much excitement among survivors, and some told me that they felt that the region was just being used to gain sympathy for the Tokyo 2020 bid.

In fact, before 3.11 and the Tokyo 2020 Olympics, residents of Tohoku have long had a conflicted relationship with Tokyo and local discourses frame the region as strong-willed and independent but always taken advantage of by the metropole. As the anthropologist William Kelly notes, "resilience, resistance, resolve and resourcefulness have characterized the Northeast from the deep past to the contemporary present." Among the older generations this is particularly so. There is a strong sense that the rural northeast has always been an afterthought to the urban glut of Tokyo, and that the Tohoku people have sacrificed themselves through food production and energy production to supply the bloated metropolis - even as they grudgingly acknowledge that their economic reliance is interdependent, and even as young people themselves increasingly leave Tohoku for Tokyo. Thus, Tokyo 2020 is the most recent spark to reignite these longstanding debates.

\section{The host town project: afterthought or future hope?}

The coastal regions in Tohoku that were hardest hit by the 3.11 disaster are the most vocal in their skepticism of hosting the 2020 Olympics in Tokyo, but there are also many other municipalities in the northeastern region where residents feel disconnected from the entire Olympic project happening 300 or more kilometers away. These are precisely the areas that the government hopes to envelope in the Olympic embrace through various "host town" programs (see Figure 30.1).

There have been several strategies for whipping up interest in the Olympics in far-flung corners of the country. The Japanese government has tried to encourage the involvement of communities outside of Tokyo through the "host town" program, whereby a municipality hosts training camps and intercultural exchanges with the Olympic teams from other countries, forging new international opportunities and connections. There is also the "Arigato Host Town for Supporting Reconstruction" program, which aims to encourage exchange between foreign nations that provided support after 3.11 and the local municipalities which benefited from their aid. As of February 2020, 479 host towns have been selected across Japan, welcoming athletes from 163 countries and territories. ${ }^{3}$

These host town schemes offer participating communities a sense of involvement by building direct person-to-person relationships between 


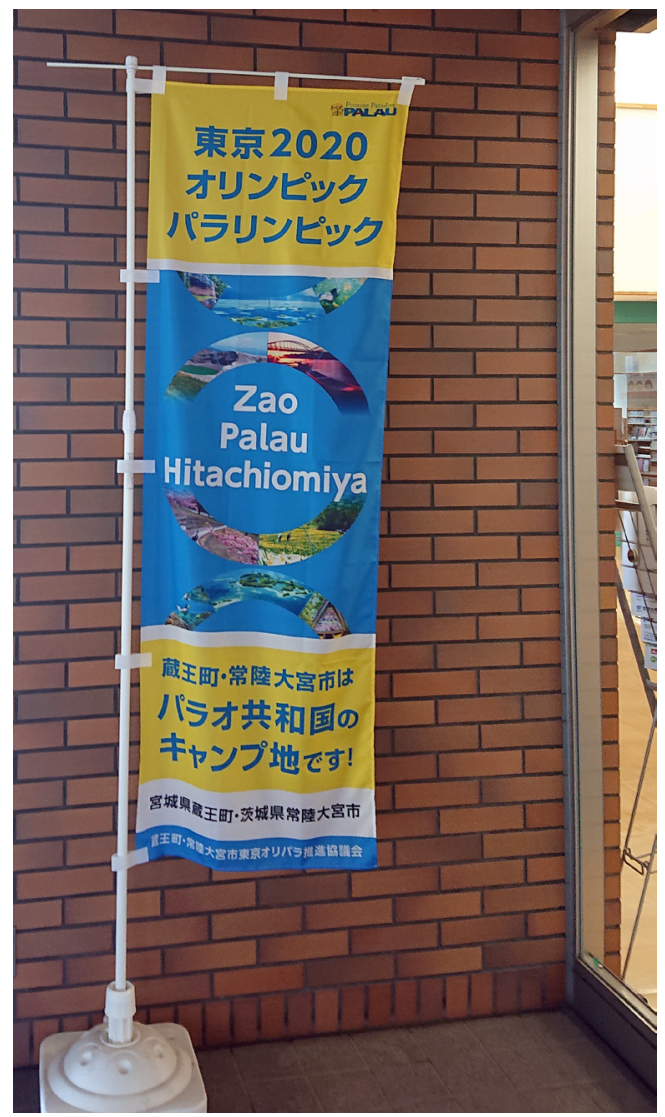

Figure 30.1 Palau - Hitachiomiya city host town banner, at Zao townhall, 2019.

Source: (C) Isaac Gagné.

citizens and Olympians from around the world. Yet the scale of their activities, the level of local interest, and the amount of effort each municipality puts into the schemes vary widely. Most host town applications in Tohoku are initiated by the local mayors, and there is no monetary incentive from the national government for standard host towns. Instead, host towns must redirect their own discretionary funds.

One of the common characteristics among Tohoku host towns is that most reported a general lack of interest in the Olympics and an ambivalent or somewhat negative attitude toward the Olympics itself among residents. 
At the same time, the relevant offices in charge of the host town activities in most municipalities were eager to increase awareness about their partner country among local residents. They arranged various speaking events by Olympic athletes, training camps for youth, collaborative school projects connecting local and overseas students, and hosted fairs showcasing goods from the other country.

For their part, host town mayors seemed eager to raise their political profiles and hoped to boost tourism to their regions. However, most of the municipal offices in charge of the actual projects confessed that they saw little possibility of linking their far-flung towns to any post-Olympic tourism boom, especially given the lack of convenient transportation to many of the rural communities in the northeast.

And as for Tokyo 2020 as the "Recovery Olympics," many I spoke with in Natori and Zao in particular remained skeptical and continued to wonder what exactly becoming a host town would do for their daily lives and their communities in the long run. This was echoed in a 2018 poll of municipal leaders in the affected areas, which found that $71.3 \%$ felt that the "Recovery Olympics ethos" remained "unclear and unfocused." Indeed, there is a sense among many Tohoku residents that "Recovery Olympics" is an empty slogan that has just co-opted the regions' hardships for the benefit of Tokyo, a sentiment further strengthened by the fact that only 12 out of the 42 municipalities that were seriously affected by the 3.11 disaster were interested in joining the "Arigato Host Town" scheme, with the majority answering that they were "still not at a stage ready to consider such things."

\section{Tokyo 2020: the Olympics as national glue or regional solvent?}

So is Tokyo 2020 the glue that will bring the nation together after increasing regional disparities and the catastrophic events of 3.11? Or will it become the corrosive solvent that further separates the shrinking regions from the power-hungry metropole? As the diverse experiences of host towns and "Arigato Host Towns" reveal, the image of Tokyo 2020 among regional residents is not a simple matter of excitement or resentment. The municipalities in Tohoku that are completely disconnected from the Olympic project and have no host town status are likely the most skeptical, or at best the least interested in the Olympics. Likewise, since there are no special funds offered to standard host towns, they must divert their own discretionary funds, which also provokes skepticism among residents, especially in disaster areas.

The positive effects of the host town schemes seem to hinge on the successful engagement of local actors. Rather than being a program linked up 
with the national project of the Olympics, the host towns in Tohoku seem to be mostly interested in deepening their cross-cultural exchange activities and connections with other countries beyond Olympic sports. In this sense, the host town schemes do not seem to contribute much to making the Olympics a nationally shared event, but rather they seem to be variously adapted to turn the Olympics into local projects for "internationalizing" regional communities by building or strengthening overseas connections, or even enhancing awareness of existing diversity within their communities. Indeed, the strongest impact seems to lie in familiarizing the "foreign" and creating person-to-person ties, especially among schoolchildren and civil society groups.

Ultimately, the view from the sidelines of the Tokyo 2020 Olympics in northeastern Japan may not even be oriented toward Tokyo after all. For many municipalities in Tohoku, becoming a host town does not mean that they are letting themselves be coopted by a metropolitan-centered Olympics project for the benefit of Tokyo, nor that they are hoodwinked by the illusion that Olympic revenues will flow their way in the form of increased tourism. Tohoku residents are fully aware that they are far from center field in the Olympics action. Instead, local actors seem to be looking beyond 2020 to various horizons: mayors to the future of their political careers; sports clubs and companies to the future of international connections; and schools to the future of their students on the global stage. While the 2020 Olympics may not become the "Recovery Olympics" that will restore disaster-stricken regions to their (retrospectively imagined) halcyon pre-3.11 days, for resourceful host towns the Olympics may still be an important opportunity for reorienting local residents' awareness towards the future of their communities in a globalizing world.

\section{Notes}

1 Tsurushima, Miho and Saito, Takanobu. 2017. "Expectations and consciousness of the 2020 Tokyo Olympics and Paralympics." NHK Hōsō Bunka Kenkyūjo: Hōsō Kenkyū to Chōsa: November.

2 Kelly, William W. 2012. "Tohoku's futures: Predicting outcomes or imagining possibilities?." The Asia Pacific Journal 10, 10(2), March 5. https://apjjf. org/2012/10/10/William-W.-Kelly/3703/article.html.

3 Tokyo 2020 Olympics host town webpage: www.kantei.go.jp/jp/singi/ tokyo2020_suishin_honbu/hosttown_suisin/index_e.html.

4 Kahoku Shinbun. 2018. "7 years since the disaster: A survey of heads of disaster-stricken areas finds $70 \%$ do not see the "recovery ethos." March 1. 